\title{
autêntica
}

\author{
ARTIGOS
}

\section{POLÍTICAS DE FORMAÇÃO DE FORMADORES PARA EDUCAÇÃO DE JOVENS E ADULTOS (EJA) NO PLANO NACIONAL DE EDUCAÇÃO PNE 2014-2024}

Ada Augusta Celestino Bezerra Márcia Alves de Carvalho Machado

RESUMO: A formação de formadores representa antigo desafio e relaciona-se à eficácia das políticas educacionais implementadas pelo Estado brasileiro. O PNE constitui-se em importante instrumento para enfrentar os desafios impostos à área educacional, entre eles os da formação de formadores da EJA. O objetivo deste trabalho é analisar conquistas e perdas do processo coletivo que precedeu o PNE 2014-2024, suas contradições, desafios e possibilidades nas instâncias locais e estaduais, no que se refere à formação de formadores para a EJA. O foco recai na responsabilização das universidades e demais instituições de educação superior para com a formação do professor da EJA, nem sempre contemplada nos projetos pedagógicos das licenciaturas. A história demonstra a necessidade de priorização da educação básica, especialmente da EJA, frente às novas demandas do sistema educacional articulado que se quer construir com a participação ativa dos formadores de formadores num processo contextualizado e pertinente.

PALAVRAS-CHAVE: Educação de Jovens e Adultos. Formação de Formadores. Plano Nacional de Educação. Políticas Educacionais.

\begin{abstract}
The training of teachers represents old challenge and relates to the effectiveness of the educational policies implemented by the Brazilian State. The NEP is an important instrument to stand up to the challenges placed to the educational area, among them the training of teachers of YAE. The objective of this study is to analyze gains and losses of the collective process that preceded the NEP 2014-2024, its contradictions, challenges and opportunities in local and states, in relation to the training of teachers for the YAE. The focus is on responsibility of universities and other institutions of college education to the education of teachers of YAE. It is, not always pondered in the pedagogical projects of undergraduate courses. The story demonstrates the need for prioritization of basic education, especially of the YAE, forefront to the new demands of the educational system articulated that if you want to build with the active participation of trainers of teachers in contextualized and relevant method.
\end{abstract}

KEYWORDS: Youth and Adult Education. Training of Trainers. National Education Plan. Educational Policies. 


\section{INTRODUÇÃO}

Nossa experiência na área de Educação de Jovens e Adultos leva-nos à preocupação com as políticas educacionais sob a ótica da formação dos formadores para enfatizar a responsabilidade das universidades e demais instituições de educação superior (IES) para com a formação inicial e continuada do professor para essa modalidade de educação básica, nem sempre contemplada nos projetos pedagógicos dos cursos de licenciatura.

Neste artigo, entendemos o Plano Nacional de Educação como um conjunto de decisões, metas e estratégias definidas em função de uma política educacional que visa à construção de um sistema nacional articulado de educação e comprometido com a transformação social e econômica do país. Temos como objetivo analisar conquistas e perdas do processo amplamente coletivo que precedeu o PNE 2014-2024, suas contradições, desafios e possibilidades nas instâncias locais e estaduais, no que se refere à formação de formadores para a Educação de Jovens e Adultos (EJA). O pressuposto é que o PNE contempla predominantemente os interesses do Governo instalado e as políticas que põe em prática, não obstante as contribuições da sociedade civil.

O tema formação de formadores na base de dados Web Scopus ${ }^{1}$ tem registrado apenas três títulos de artigos publicados, os quais, analisados, indicam lacunas a serem preenchidas por pesquisas na área de Ciências Humanas e Sociais. Desses artigos localizados, nenhum deles alude à formação de formadores para Educação de Jovens e Adultos, o que indica a relevância deste estudo.

Os problemas que hoje permeiam essa formação de formadores representam antigos desafios e problemas acumulados, relacionados à ineficácia e às deficiências das políticas educacionais implementadas pelo Estado brasileiro, com destaque às dificuldades de formação de formadores para a Educação Básica de um modo geral e à emergência da Educação de Jovens e Adultos.

\section{INEFICÁCIA DAS POLÍTICAS EDUCACIONAIS E A EMERGÊNCIA DA EJA}

Pelo menos há oito décadas, o Manifesto dos Pioneiros da Educação Nova (1932), ao elaborar um diagnóstico sobre a educação do início do século XX, já denunciava a existência de pessoas na função docente sem qualquer preparação para a profissão, desde o ensino primário ao superior. Existia, portanto, um sentimento de descuido quanto à preparação dos professores, "como se a função educacional, de todas as funções públicas a mais importante, fosse a única para cujo exercício não houvesse necessidade de qualquer preparação profissional" (MANIFESTO, 2006, p. 200).

Atualmente, verificamos que no interior do próprio "sistema educacional", embora se discuta a inexistência desse sistema², encontram-se contradições nas oportunidades de formação oferecidas aos professores, desde a inicial até a continuada, sendo o déficit ainda maior quando analisamos a modalidade da EJA.

\footnotetext{
1 A Scopus (SciVerse Scopus), propriedade da Elsevier, é a maior base de dados bibliográficos a respeito da literatura científica revisada por pares, contemplando 50 milhões de registros (dos quais 29 milhões incluem referências, até 1995 - 84\% também com resumos - e 21 milhões anteriores a 1996 que recuam até 1823). Integra, em resultados de busca, 545 milhões de resultados científicos da web e 25,2 milhões de patentes de 5 escritórios (Escritório Americano de Marcas e Patentes (USPTO), Escritório Europeu de Patentes (EPO), Escritório Japonês de Patentes (JPO), Organização Mundial da Propriedade Intelectual (OMPI) e Escritório de Propriedade Intelectual do Reino Unido (IPO), conforme http://www.americalatina.elsevier. $\mathrm{com} / \mathrm{sul} / \mathrm{pt}$-br/scopus.php . Cobre a produção de pesquisa do mundo nas áreas de ciência, tecnologia, medicina, ciências sociais e artes e humanidades. Alcança 21.000 títulos e mais de 5.000 editoras internacionais, incluindo a cobertura de 16.500 revistas peer-reviewed (http://www.americalatina. elsevier.com/sul/pt-br/scopus.php).
}

2 SAVIANI, Dermeval. Educação brasileira: estrutura e sistema. 10. ed. Campinas: Autores Associados, 2008. 


\section{autêntica}

Nossa concepção de educação de jovens e adultos é a de um processo formativo como prática social ampla e humanizante que não se limita à preparação para o mercado de trabalho, conforme a Teoria do Capital Humano, nem à informalidade da educação ao longo da vida. Ou seja, defendemos um modelo próprio para a EJA, de educação formal, em uma concepção "voltada para a continuidade permanente de estudos até o nível superior, diferentemente da perspectiva não formal de educação ao longo da vida" (MACHADO, 2015, p. 261).

As políticas educacionais empreendidas no país nas décadas subsequentes estiveram, acima de tudo, voltadas ao plano macro de Estado ${ }^{3}$ que privilegiava a expansão do modelo capitalista na busca do crescimento econômico nacional por meio da formação de uma mão-de-obra instrumentalizada para o desenvolvimento da indústria. A educação de jovens e adultos nesse contexto visava exclusivamente à qualificação dessa mão-de-obra, sem contudo apresentar eficácia quanto aos objetivos.

Embora tenha trazido medidas que denotavam novos horizontes em termos de direitos para a população, no âmbito econômico, social e cultural, a Constituição de 1934 foi considerada a primeira constituição liberal do país, com implicações, inclusive, no campo educacional. O documento incorporava alguns aspectos dos ideais dos pioneiros da educação nova, expressos no Manifesto e estabelecia a necessidade do Plano Nacional de Educação, que veio, em 1937, a se materializar como primeiro Plano Nacional de Educação com o título Código da Educação Nacional. Para Saviani (1999, p. 126):

[...] do ponto de vista da forma, o referido 'Plano' correspondia ao espírito da Constituição de 1934 já que aí, como se assinalou, a ideia de plano coincidia com as próprias diretrizes e bases da educação nacional. Quanto ao conteúdo, entretanto, ele já se afastava da ideia dos pioneiros que prevalecia, também, na Associação Brasileira de Educação, aproximando-se da orientação que irá predominar durante o Estado Novo. Assim, enquanto para os educadores alinhados com o movimento renovador o plano de educação era entendido como um instrumento de introdução da racionalidade científica na política educacional, para Getúlio Vargas e Gustavo Capanema o plano se convertia em instrumento destinado a revestir de racionalidade o controle político-ideológico exercido através da política educacional. Esse controle sedimentou-se durante a ditadura do Estado Novo num projeto político centralizador sob a bandeira de uma identidade nacional associada à necessidade de renovação e modernização, sempre permeada pela intervenção do Estado.

Somente na década de 1960, com a luta dos movimentos populares em favor da transformação social, da educação, em especial dos adultos, registrou-se novo esforço de reordenamento da educação nacional e da conscientização popular. A ditadura militar de 1964 cerceou esse amplo movimento e instituiu um ordenamento liberal, autoritário e repressivo como contraponto, iniciando com a Reforma Universitária (1968), seguida da Lei $n^{\circ} 5.692$, de 1971, que tornou compulsória a qualificação profissional no então ensino de segundo grau, visando à contenção do acesso ao ensino superior das classes média e de baixa renda e ainda enfatizou a necessidade de escolarizar os adolescentes e adultos sem instrução, pela organização do ensino supletivo. Essa lei foi complementada pela Lei $n^{\circ}$ 7.044, de 1982, com a institucionalização das habilitações profissionais.

Essa legislação, conforme Scheibe e Durli (2011), apesar de destinada em especial à regulamentação dos ensinos de $1^{\circ}$ e $2^{\circ}$ graus, preconizou um esquema de formação de professores diferenciado. O Capítulo V, art. 29, estabeleceu que a formação para esses ensinos seria realizada em níveis que se elevariam progressivamente, ajustando-se às diferenças culturais e regionais do país, entre outros aspectos.

3 Compreende-se por Estado a organização política que, num momento histórico conquista, afirma e mantém a soberania sobre um determinado território, exercendo entre suas funções a regulação, coerção e controle social - sendo essas mutáveis e de configurações específicas; na transição para a modernidade tornaram-se gradualmente indispensáveis ao funcionamento, expansão e consolidação do capitalismo (AFONSO, 2000). 


\section{autêntica}

Daí as licenciaturas terem sido pensadas sob modelos diferenciados, desde as licenciaturas plenas (com quatro anos de duração, esquema três anos de conteúdo específico + um ano de conteúdo pedagógico), às de curta duração (com dois anos e meio em Ciências, Estudos Sociais, Letras), até as experiências de três anos, inclusive para o curso de Pedagogia. De início, os cursos de Pedagogia eram sempre pensados juntamente com as demais licenciaturas, mas, com o passar dos anos, houve um descolamento das chamadas áreas de ensino, com repercussões na pós-graduação, o que resultou em perda epistemológica para a área de Educação na formação dos formadores.

Na Pedagogia, houve preocupação nos respectivos projetos pedagógicos com a formação para a Educação Infantil, para os Anos Iniciais do Ensino Fundamental, para a Educação de Jovens e Adultos, para a Educação Especial e para a Educação Inclusiva. Hoje, a EJA e a Educação Inclusiva representam modalidades da Educação Básica e as demais licenciaturas não têm formação nessa perspectiva. Permanecem ausentes conteúdos que formem os formadores para o trabalho com adultos, nos cursos de formação inicial, salvos alguns cursos de Pedagogia, o que aponta para a necessidade de formação inicial emergencial para os formadores atuarem nos programas e da oferta de formação continuada em serviço.

No contexto dos governos neoliberais e de suas políticas, foi aprovada a LDB n 9.394/1996, após oito anos de negociações e embates entre governo, educadores e movimentos sociais, ao final dos quais foram desprezados os acordos e os consensos estipulados com a sociedade civil. No que se refere à EJA, a lei, de forma simplista, destinou-lhe pouco espaço, porém garantiu sua inclusão como modalidade da Educação Básica. O resultado da omissão dos governos brasileiros na regulamentação e organização dessa modalidade resulta na constatação de que:

[...] mesmo após a promulgação em 1996 da nova Lei de Diretrizes e Bases da Educação, n 9.394, a cultura escolar brasileira ainda encontra-se impregnada pela concepção compensatória de educação de jovens e adultos que inspirou o ensino supletivo, visto como instrumento de reposição de estudos não realizados na infância ou adolescência. Ao focalizar a escolaridade não realizada ou interrompida no passado, o paradigma compensatório acabou por enclausurar a escola para jovens e adultos nas rígidas referências curriculares, metodológicas, de tempo e espaço da escola de crianças e adolescentes, interpondo obstáculos à flexibilização da organização escolar necessária ao atendimento das especificidades desse grupo sociocultural. Ao dirigir o olhar para a falta de experiência e conhecimento escolar dos jovens e adultos, a concepção compensatória nutre visões preconceituosas que subestimam os alunos, dificulta que os professores valorizem a cultura popular e reconheçam os conhecimentos adquiridos pelos educandos no convívio social e no trabalho (DI PIERRO, 2005, p. 1118).

Atendendo ao disposto nessa LDB 9.394/1996, foi elaborado o PNE 2001 - 2010, cuja construção foi desenvolvida em meio a amplos debates desde 1996. Sua aprovação só se efetivou em 9 de janeiro de 2001, pela Lei no 10.172. No entendimento de Saviani (2012, p. 3), o PNE regula o Sistema Nacional de Educação, cabendo "formular as diretrizes, definir as metas e indicar os meios pelos quais as metas serão atingidas". Esse é considerado, de fato, o primeiro plano da educação no Brasil e teve vigência de dez anos, mas foi mutilado ao ter nove vetos da Presidência da República, em especial porque os vetos incidiam sobre pontos nevrálgicos, como o financiamento (SAVIANI, 2007).

Machado (2009) aponta para a contradição no processo de legalidade e legitimidade da EJA pelo governo FHC, pois o próprio governo apresenta vetos à lei que criou o Fundo de Manutenção e Desenvolvimento do Ensino Fundamental e de Valorização do Magistério (Fundef), atingindo diretamente a EJA. Os vetos de FHC, que incidiram sobre os recursos da União para o investimento na educação, impediram que as matrículas de 


\section{autêntica}

EJA fossem consideradas na redistribuição dos recursos desse Fundo, ferindo o direito explicitado no art. $4^{\circ}$ da LDB/1996 (MACHADO, 2009, p. 20).

Em relação à formação de professores, a lei fez emergir a ameaça da extinção do curso de Pedagogia como consolidação da desvalorização do magistério, colocando-se na contramão de décadas de lutas dos educadores para reformular os cursos de formação. O art. 62 da LDB 9394//1996 estabeleceu que a formação de docentes para atuar na Educação Básica seria em nível superior, em curso de licenciatura, de graduação plena, em universidades e institutos superiores de educação, permitida como formação mínima para o exercício do magistério na educação infantil e nos anos iniciais do ensino fundamental aquela em nível médio, na modalidade Normal.

Ainda hoje encontramos programas destinados à EJA, a exemplo do Programa Brasil Alfabetizado (PBA), que, em detrimento das próprias diretrizes e legislações, possui, como formadores, pessoas com o nível médio de escolarização (sem sequer o Magistério Normal) ou, até mesmo em alguns casos, apenas com o nível fundamental. Essas são ambiguidades pertinentes ao Estado pós-neoliberal (governos Lula e Rousseff), que desvelam a hegemonia de uma nova ideologia que avança pelas ideias neoliberais com uma nova forma de dominação4. Essa nova dominação mantém caraterísticas fundamentais do neoliberalismo, como a descentralização das ações, as parcerias público-privado e a subserviência às recomendações de organismos internacionais, e, ao mesmo tempo, incorpora novas formas de governação com características como renovações constantes de orientações e legislações das políticas, trabalho docente com caráter de voluntarismo - considerado um dos fatores para equacionar parte dos problemas da educação e de uma formação de qualidade - em detrimento ao profissionalismo.

Esses e outros problemas acentuam as dificuldades pertinentes à formação de formadores da EJA e indicam a falta de cuidado para com a modalidade, a respeito da qual, arriscamos dizer, está longe de estagnar. Embora as estatísticas da Educação Básica apontem para uma redução do número de matriculas na EJA, em 2013 foram 3.772.670 e, em 2014, as matriculas foram 3.592.908, conforme dados do Instituto Nacional de Estudos e Pesquisas Educacionais Anísio Teixeira Sinopses Educação Básica (INEP). Essa queda de aproximadamente $5 \%$ nas matriculas não significa necessariamente que a população jovem e adulta está se escolarizando, mas pode representar um desinteresse dessa faixa etária pela escolarização, ou ainda, o encaminhamento deles para cursos profissionalizantes.

Conforme os dados da Pesquisa Nacional por Amostra de Domicílios (PNAD), levantados pelo Instituto Brasileiro de Geografia e Estatística (IBGE), a população na faixa etária de 15 ou mais anos, em 2012, era de 151 milhões de pessoas e, em 2013, houve um aumento desta população para 156 milhões de pessoas. Em 2012, dessa faixa etária, aproximadamente 13,163 milhões de pessoas eram analfabetas, número que cresceu em 2013 para 13,335 milhões - isso sem levarmos em conta o analfabetismo funcional que abriga outros milhões de pessoas consideradas como alfabetizadas.

Pelo exposto, evidencia-se que os governos que estiveram e estão à frente das políticas educacionais pouco têm considerado ou valorizado o trabalho com a EJA. As especificidades dessa modalidade devem ser urgentemente repensadas, pois o país está envelhecendo, muitos jovens estão fora do ambiente escolar e, provavelmente, serão os adultos sem escolarização ou analfabetos funcionais de amanhã. Nesse contexto,

4 Para melhor compreensão dessa nova forma de dominação ver OLIVEIRA, Francisco; BRAGA, Ruy; RIZEK, Cibele. Hegemonia às avessas: economia, política e cultura na era da servidão financeira. São Paulo: Boitempo, 2010. 


\section{autêntica}

a formação de formadores para a EJA torna-se cada vez mais premente como ação das universidades ou das agências formadoras dos profissionais da educação, representando, já nos últimos anos, espaço amplo de estágio para as licenciaturas e mesmo crescente segmento de funções docentes.

\section{O PNE 2001-2010: INVIABILIZADO PELOS VETOS GOVERNAMENTAIS}

Fazendo uma retrospectiva do PNE 2001-2010, verificamos que a preocupação com a formação para a modalidade de EJA foi contemplada nos objetivos, embora as expectativas tenham sido frustradas. Nesse período, conforme demonstram Filgueiras, Gonçalves (2007) e Frigotto (2011), o governo brasileiro - quer o rotulado como neoliberal, quer o dito pós-neoliberal -, centraram suas atenções no ajuste fiscal, nas metas de inflação e no câmbio flutuante, em razão dos compromissos com o capital financeiro e com as políticas assistencialistas. Corroboram essa análise Bonamigo et al (2011, p. 5):

[...] o setor da saúde e da educação perderam participação relativa no orçamento da União entre 2000 e 2006, enquanto o programa Bolsa Família dobrou a sua participação. O governo petista, mais do que o seu antecessor, percebeu a eficácia dessas despesas no amortecimento das tensões sociais que se desenvolvem em respostas ao projeto neoliberal. Por meio de políticas assistencialistas, o governo apostou no amortecimento dos conflitos, mantendo as camadas populares em constante estado de dependência, permitindo assim sua direção política.

O objetivo/meta 7 visava assegurar aos sistemas estaduais de ensino, em regime de colaboração com os demais entes federativos, a manutenção de programas de formação de educadores de jovens e adultos, capacitados para atuar de acordo com o perfil da clientela e habilitados para, no mínimo, o exercício do magistério nas séries iniciais do ensino fundamental, de forma a atender a demanda de órgãos públicos e privados envolvidos no esforço de erradicação do analfabetismo (BRASIL, 2001).

Estava previsto no objetivo/meta 10 que, onde ainda não existiam condições para formação em nível superior de todos os profissionais necessários para o atendimento das necessidades do ensino, fossem estabelecidos cursos de nível médio, em instituições específicas, que observassem os princípios do plano e preparassem pessoal qualificado para a educação infantil, para a educação de jovens e adultos e para as séries iniciais do ensino fundamental, prevendo a continuidade dos estudos desses profissionais em nível superior (BRASIL, 2001).

O objetivo/meta 16 apontava para a EJA, declarando visar promover, nas instituições públicas de nível superior, a oferta, na sede ou fora dela, de cursos de especialização voltados à formação de pessoal para as diferentes áreas de ensino e, em particular, para a educação especial, a gestão escolar, a formação de jovens e adultos e a educação infantil (BRASIL, 2001).

Garantir, no prazo de cinco anos, que todos os professores em exercício na educação infantil e nas quatro primeiras séries do ensino fundamental, inclusive nas modalidades de educação especial e de jovens e adultos, possuam, no mínimo, habilitação de nível médio (modalidade normal), específica e adequada às características e necessidades de aprendizagem dos alunos, era o conteúdo do objetivo/meta 17 (BRASIL, 2001).

Esses objetivos/metas do PNE anterior, além de não serem viabilizados, eram contraditórios entre si e em relação à formação docente para a EJA, ferindo o artigo 62 da LDB 9.394/1996 e a tese consolidada da Associação Nacional pela Formação dos Profissionais da Educação (ANFOPE) quanto aos profissionais da Educação Básica terem, no mínimo, a formação em graduação (licenciatura).

De acordo com os dados do INEP, a partir da Sinopse Estatística da Educação Básica 2001, no início do primeiro plano, conforme Tabela 1, existiam 159.737 docentes atuando na EJA. Desse grupo, 840 professores 


\section{autêntica}

ainda não possuíam o ensino fundamental, 3.526 tinham apenas o fundamental e representavam 2,2\% do total dos professores e 53.739, o nível médio completo, representando 33,64\% do total dos professores. Os docentes com nível superior, conforme determina o artigo 62 da LDB 9.394/1996, eram 101.632 representando a maioria dos professores, $62 \%$.

TABELA 1 - NÚMERO DE FUNÇÕES DOCENTES NA EJA, POR NÍVEL DE FORMAÇÃO, BRASIL, 2001 A 2014

\begin{tabular}{|c|c|c|c|c|c|c|c|c|c|}
\hline \multirow{3}{*}{ Ano } & \multirow{3}{*}{ Total } & \multicolumn{8}{|c|}{ Funções Docentes na Educação de Jovens e Adultos } \\
\hline & & \multicolumn{4}{|c|}{ Fundamental } & \multirow{2}{*}{$\begin{array}{c}\text { Médio } \\
\text { completo }\end{array}$} & \multirow{2}{*}{$\%$} & \multirow{2}{*}{$\begin{array}{l}\text { Superior } \\
\text { Completo }\end{array}$} & \multirow{2}{*}{$\%$} \\
\hline & & Incompleto & $\%$ & Completo & $\%$ & & & & \\
\hline 2001 & 159.737 & 840 & 0,53 & 3.526 & 2,2 & 53.739 & 33,64 & 101.632 & 63,62 \\
\hline 2010 & 261.732 & & & 1.003 & 0,4 & 55.444 & 21,18 & 205.290 & 78,44 \\
\hline 2014 & 250.844 & & & 316 & 0,1 & 41.117 & 16,39 & 209.411 & 83,48 \\
\hline
\end{tabular}

Fonte: INEP, 2001; 2010; 2014

Ao fim do plano, em 2010, o número de docentes apenas com nível fundamental era de 1.003, ou seja, não foi atingido o objetivo/meta 17, que era garantir que todos os professores da EJA tivessem, ao menos, a formação no nível médio. É inconcebível que as ações para atingimento dessa meta não tenham dado conta de formar em nível médio apenas 1.003 professores que ainda possuíam formação apenas até o nível fundamental.

Esse resultado demonstra o desinteresse do governo brasileiro em promover a progressão docente nessa modalidade e a consequente elevação da qualidade da educação básica. É preciso, também, investigar as causas que levaram o próprio docente a não exigir de sua vinculação administrativa (federal, estadual ou municipal) o cumprimento da meta, bem como das associações de classe e representantes da sociedade civil, que durante toda a vigência do plano, dez anos, poderiam acompanhar e serem mais eficazes nessa função.

Após quatro anos do encerramento da vigência desse PNE, em 2014, também conforme a Tabela 1, o Brasil ainda possuía 316 professores da EJA apenas com o nível fundamental e 41.117 professores com nível médio, ou seja, permanecia o desacordo com as determinações da LDB 9.394/1996.

A construção de um novo PNE, necessariamente, acabou assumindo o desafio de fazer superar a ineficiência do plano anterior em relação à formação de professores da EJA. Relativamente aos professores que possuíam a formação superior, totalizando 209.411, o que representava 83,48\% dos profissionais da Educação Básica, 120.602 possuíam apenas a graduação, 83.097 já tinham especialização e os demais 5.712 eram mestres ou doutores. No entanto, chamamos a atenção para o que já foi mencionado no início deste artigo quanto a muitos professores com ensino superior não possuírem especialização na área em que atuam.

Comungamos com Saviani (2014c) quando afirma que esse plano foi apenas uma carta de intenções no qual a lei que o instituiu permaneceu letra morta, não possuindo expressão nas medidas de política educacional e na vida das escolas. Os vetos do governo FHC inviabilizaram a execução do PNE 2001-2010, assim como a conivência dos governos Lula, que poderia ter vetado esses vetos.

\section{O PNE 2014-2024 E A FORMAÇÃO DE FORMADORES DA EJA}

Sendo o PNE 2014-2024 fruto de um processo marcado por conferências e participação coletivas, em curso desde a CONAE 2010, com representação dos diversos segmentos da sociedade civil organizada, inclusive dos 


\section{autêntica}

formadores e das agências formadoras, carreou muitas expectativas de avanços também nesse sentido. Seria ele um grande instrumento de intervenção social para promover o enfrentamento dos desafios já mencionados relativos à valorização das licenciaturas, melhoria da formação docente e da qualidade da educação brasileira.

Sua tramitação no Congresso Nacional implicou perdas significativas para os movimentos dos educadores, sendo assinalada por interesses políticos e econômicos que prevaleceram sobre os sociais. O documento foi fruto de disputas ideológicas e interesses de classes antagônicas. Aprovado pela Lei n 13.005, com 20 metas e 254 estratégias, entrou em vigor em 25 de junho de 2014 o atual Plano Nacional da Educação (2014-2024).

Com relação à formação especifica para EJA, verifica-se que se consolida o total descaso das políticas educacionais com a formação dos profissionais dessa modalidade, quer seja inicial, quer seja continuada. O novo PNE foi aprovado tendo 10 diretrizes e 20 metas, cada uma com suas respectivas estratégias de alcance.

Entre as diretrizes estão a erradicação do analfabetismo a superação das desigualdades educacionais, com ênfase à promoção da cidadania e à erradicação de todas as formas de discriminação; a melhoria da qualidade da educação; a valorização dos profissionais da educação e a promoção dos princípios do respeito aos direitos humanos, à diversidade e à sustentabilidade socioambiental.

Pela Meta 9 - relativa à alfabetização da população de 15 anos ou mais de idade - e pela Meta 10 - referente ao aumento das matrículas na EJA -, definiu-se entre suas estratégias:

\footnotetext{
9.8) assegurar a oferta de educação de jovens e adultos, nas etapas de ensino fundamental e médio, às pessoas privadas de liberdade em todos os estabelecimentos penais, assegurando-se formação específica dos professores e das professoras e implementação de diretrizes nacionais em regime de colaboração [...] 10.10) orientar a expansão da oferta de educação de jovens e adultos articulada à educação profissional, de modo a atender às pessoas privadas de liberdade nos estabelecimentos penais, assegurando-se formação específica dos professores e das professoras e implementação de diretrizes nacionais em regime de colaboração [...] (BRASIL, 2014).
}

Assim, verifica-se a preocupação em incluir os jovens e adultos privados de liberdade na EJA e de assegurar aos professores a formação específica para o trabalho a ser desenvolvida com eles. No entanto, entendemos que essa exigência está muito mais atrelada a novas especificidades que a educação de pessoas privadas de liberdade exige do que às preocupações com a EJA. Embora mencionem de forma geral todos os profissionais da Educação Básica, as Metas 15 e 16 não especificam as modalidades.

Nelas se expressam, na nossa concepção, os objetivos mais importantes e os mais difíceis de serem alcançados. Com a Meta 15, pretende-se garantir, em regime de colaboração e no prazo do primeiro ano de vigência do plano, uma política nacional de formação dos profissionais que assegure a todos os professores formação específica de nível superior (licenciatura) na área de conhecimento em que atuam. A Meta 16 propõe formar até 2024, na pós-graduação, 50\% dos professores da Educação Básica, garantindo a todos os profissionais a formação continuada em sua área de atuação, considerando-se as necessidades, demandas e contextualizações dos sistemas de ensino. Contempla-se aí também a EJA, o que garantiria especialização a muitos que atuam na modalidade sem a formação especifica. Contudo, não se garante que será tratada como modalidade de ensino/conteúdo e não apenas como área de conhecimento.

Destacamos as metas 17, 18 e 20 que se articulam com as metas já analisadas para formação inicial e continuada dos professores, por dizerem respeito à valorização e ao plano de carreira docente e, por fim, ao financiamento 


\section{autêntica}

da educação. Conforme dados da PNAD (2013), os professores da Educação Básica possuem rendimento de apenas 53,7\% em relação ao rendimento médio de profissionais com o mesmo nível de escolaridade.

As estratégias para o enfrentamento desse tipo de problema são o acompanhamento da atualização progressiva do valor do piso salarial nacional; implementação pelos poderes executivos de planos de carreira para os profissionais do magistério das redes públicas de Educação Básica; e ampliação da assistência financeira específica da União aos entes federados para implementação de políticas para esses fins, dentre outras.

Com relação aos planos de carreira, foi definido pela Meta 18 assegurar, no prazo de dois anos, a existência de planos de carreira para os profissionais da Educação Básica e Superior pública de todos os sistemas de ensino. Para os profissionais da Educação Básica pública, deve ser tomado como referência o piso salarial nacional profissional. Entre as estratégias para atingimento dessa meta, destacamos a implantação, nas redes públicas de Educação Básica e Superior, acompanhamento dos profissionais iniciantes (durante estágio probatório) e realização nesse período de curso de aprofundamento de estudos na área de atuação do professor, com destaque aos conteúdos a serem reconstruídos e às metodologias de ensino de cada disciplina. São necessários, ainda, incentivos para qualificação profissional, inclusive no nível da pós-graduação stricto sensu, e atenção às especificidades socioculturais das escolas das áreas rurais e das comunidades indígenas e quilombolas no provimento de cargos efetivos para essas escolas.

Apontamos a falha da Meta 18 que não contempla as especificardes socioculturais das escolas que atuam com a EJA, por acreditarmos na importância do trabalho educativo dessa modalidade, que tende a crescer quantitativamente no país, estando a requerer uma nova qualidade. Propomos que as IES que oferecem cursos de pós-graduação stricto sensu na área de Educação oportunizem a aprovação de projetos de pesquisa que contribuam para o preenchimento de lacunas nas áreas de políticas públicas e de formação de professores com foco na EJA.

Acreditamos que as metas aqui analisadas do novo PNE não poderão ser atingidas se a Meta 20, que fixa o percentual mínimo do Produto Interno Bruto (PIB) do país, não avançar rapidamente em direção aos 10\% reclamados pela sociedade civil, de modo a viabilizar as estratégias traçadas pelo plano que dependem decisivamente da ampliação dos investimentos públicos em educação. É preocupante o atual estado de crise do país com a retração do PIB, o que repercutirá no conteúdo desse percentual para a educação.

Esclarecemos que a defesa da formação dos formadores que atuam ou atuarão na EJA pelas Universidades é tão genuína quanto a defesa de formação para qualquer outra modalidade da Educação Básica, pois o formador tem direito à formação inicial e continuada contextualizada, observadas as especificidades e demandas socialmente necessárias.

Em nosso entendimento, são metas discutíveis, porque respeitar a diversidade dos alunos, conforme estabelecido já consensualmente em todo o mundo e fixado nas diretrizes do PNE, é respeitar as especificidades da EJA. Nesse caso, a formação especifica de nível superior apenas na área de conhecimento em que atuam (Português, Matemática, História, entre outras) não é suficiente para dotar o formador da EJA de conhecimentos/saberes necessários para sua atuação com os alunos, reunidos em turmas heterogêneas, em geral com diferentes faixas etárias que variam dos 15 a mais de 60 anos de idade, ou jovens que ainda não estão inseridos no mercado de trabalho ou pessoas que trabalham, outras que já estão fora dele, às vezes trabalhadores urbanos e outros rurais etc.. Poucos são os cursos de formação inicial ou continuada que contemplam conteúdos voltados para EJA. 


\section{autêntica}

\section{EXECUÇÃO DAS METAS DO PNE QUANTO À FORMAÇÃO DOCENTE PARA A EJA}

Durante a vigência do PNE 2001-2010, merece destaque a política pública de formação docente da Universidade Aberta do Brasil, criada pelo Decreto $n^{\circ} 5.800$, de 8 de junho de 2006. Especialmente quanto à formação continuada, na pós-graduação, na pesquisa de Gatti et al (2011), constatamos a oferta de cursos de formação continuada em EJA pela Universidade Aberta do Brasil (UAB), na modalidade de Aperfeiçoamento (com no mínimo 180 horas), que objetivam oportunizar o aprimoramento da formação profissional a portadores de diplomas de formação em nível superior (Licenciatura), na categoria de Diversidade, conforme Quadro 1, a seguir.

Em 2011, eram oferecidos 163 tipos de cursos relativos à Diversidade, dos quais 19 são de EJA. No entanto, a participação dos professores nesses cursos era de 2,8\%. Entendemos que a oferta de cursos para EJA, em pós-graduação lato sensu, ou seja, Especialização, por serem mais extensos, com um mínimo de 360 horas, proporcionariam maior profundidade e novas aprendizagens nessa modalidade que requer fundamentos e abordagens epistemológicas e pedagógicas específicas para o formador, o que certamente contribuiria para a elevação da qualidade do ensino na EJA. Coadunar-se-ia, assim, a proposta com as diretrizes do PNE, além de ser mais atrativa para a carreira docente em termos de titulação e de valorização.

QUADRO 1 - DISTRIBUIÇÃO DOS CURSOS DE FORMAÇÃO DE PROFESSORES OFERECIDOS PELA UAB, POR MODALIDADE E ÁREA DE CONHECIMENTO, QUANTO À MODALIDADE APERFEIÇOAMENTO

\begin{tabular}{|c|c|c|c|}
\hline & $\begin{array}{l}\text { Número de } \\
\text { cursos de } \\
\text { formação de } \\
\text { professores }\end{array}$ & $\begin{array}{c}\text { Participação no } \\
\text { total dos cursos } \\
\text { de formação de } \\
\text { professores }\end{array}$ & $\begin{array}{l}\text { Participação no total dos } \\
\text { cursos por modalidade }\end{array}$ \\
\hline Total Geral & 690 & $100 \%$ & \\
\hline LICENCIATURA & 299 & $43,3 \%$ & $100 \%$ \\
\hline FORMAÇÃO PEDAGÓGICA & 8 & $1,2 \%$ & $100 \%$ \\
\hline ESPECIALIZAÇÃO & 138 & $20 \%$ & $100 \%$ \\
\hline APERFEIÇOAMENTO & 179 & $25,9 \%$ & $100 \%$ \\
\hline $\begin{array}{l}\text { Áreas do currículo da } \\
\text { educação básica }\end{array}$ & 10 & $1,4 \%$ & $5,6 \%$ \\
\hline $\begin{array}{c}\text { Tecnologia da informação } \\
\text { e comunicação }\end{array}$ & 6 & $0,9 \%$ & $3,4 \%$ \\
\hline Diversidade & 163 & $23,6 \%$ & $91,1 \%$ \\
\hline Educação para a diversidade & 31 & $4,5 \%$ & $17,3 \%$ \\
\hline Gênero e diversidade & 26 & $3,8 \%$ & $14,5 \%$ \\
\hline $\begin{array}{c}\text { Educação para as relações } \\
\text { étnico-raciais }\end{array}$ & 30 & $4,3 \%$ & $16,8 \%$ \\
\hline Educação ambiental & 28 & $4,1 \%$ & $15,6 \%$ \\
\hline Educação de jovens e adultos & 19 & $2,8 \%$ & $10,6 \%$ \\
\hline $\begin{array}{c}\text { Educação em direitos } \\
\text { humanos }\end{array}$ & 12 & $1,7 \%$ & $6,7 \%$ \\
\hline
\end{tabular}




\section{autêntica}

\begin{tabular}{|c|c|c|c|}
\hline Educação integral & 9 & $1,3 \%$ & $5 \%$ \\
\hline Educação do campo & 2 & $0,3 \%$ & $1,1 \%$ \\
\hline EXTENSÃO & 66 & $9,6 \%$ & $100 \%$ \\
\hline
\end{tabular}

Fonte: Adaptado de GATTI et al (2011, p. 87-88)

Visando levantar a oferta de cursos de Especialização oferecidos pelo Governo, realizamos pesquisa em dezembro/2014 na base de dados da UAB e observamos a existência de cursos de especialização para EJA e, ainda, os de aperfeiçoamento e extensão. As especializações são ofertadas em quatro regiões: Sul, Centro-Oeste, Nordeste e Sudeste, sendo oferecidas por seis Instituições de Ensino Superior (IES), conforme Quadro 2 a seguir.

As regiões Sul e Centro-Oeste ofertam cursos, cada uma delas, em duas IES e as regiões Nordeste e Sudeste, cada uma, em uma IES. As especializações são cursos com carga horárias de 360, 420 e 480 horas. A região Sul oferta o curso nos estados de Santa Catarina e do Rio Grande do Sul, sendo um total de onze polos. Na região Nordeste, o curso é ofertado no estado do Ceará, em quatro polos, e na região Sudeste a oferta acontece no estado do Espírito Santo, em onze polos. No entanto, os dois cursos da região Centro-Oeste não apresentavam oferta em qualquer polo no período da pesquisa.

QUADRO 2 - CURSOS OFERTADOS PELA UAB - DEZEMBRO/2014

\begin{tabular}{|c|c|c|c|c|c|c|}
\hline & NOME & INSTITUIÇÃO & REGIÃo & UF & $\begin{array}{l}\text { CHAMADA } \\
\text { UAB }\end{array}$ & $\begin{array}{l}\text { FORM. } \\
\text { PROF. }\end{array}$ \\
\hline & ESPECIALIZAÇÃO & & & & & \\
\hline 1 & EDUCACAO DE JOVENS E ADULTOS & IFSC & Sul & $\mathrm{SC}$ & SECAD I & Sim \\
\hline 2 & EDUCACAO DE JOVENS E ADULTOS & UFMS & $\begin{array}{l}\text { Centro- } \\
\text { Oeste }\end{array}$ & MS & SECAD I & Sim \\
\hline 3 & EDUCACAO DE JOVENS E ADULTOS & UnB & $\begin{array}{l}\text { Centro- } \\
\text { Oeste }\end{array}$ & DF & SECAD I & Sim \\
\hline 4 & $\begin{array}{c}\text { EDUCACAO DE JOVENS E ADULTOS NA } \\
\text { DIVERSIDADE }\end{array}$ & FURG & Sul & RS & SECAD II & $\operatorname{Sim}$ \\
\hline 5 & $\begin{array}{c}\text { EDUCACAO DE JOVENS E ADULTOS NA } \\
\text { DIVERSIDADE }\end{array}$ & IFCE & Nordeste & $\mathrm{CE}$ & SECAD II & Sim \\
\hline \multirow[t]{2}{*}{6} & $\begin{array}{l}\text { EDUCACAO PROFISSIONAL INTEGRADA } \\
\text { A EDUCACAO BASICA NA MODALIDADE } \\
\text { DE EDUCACAO DE JOVENS E ADULTOS }\end{array}$ & IFES & Sudeste & ES & UAB II & Sim \\
\hline & APERFEIÇOAMENTO & & & & & \\
\hline 7 & EDUCACAO DE JOVENS E ADULTOS & UEMA & Nordeste & MA & SECAD I & Sim \\
\hline 8 & EDUCACAO DE JOVENS E ADULTOS & UFF & Sudeste & RJ & SECAD I & Sim \\
\hline 9 & EDUCACAO DE JOVENS E ADULTOS & UFMA & Nordeste & MA & SECAD II & Sim \\
\hline 10 & EDUCACAO DE JOVENS E ADULTOS & UFMS & $\begin{array}{l}\text { Centro- } \\
\text { Oeste }\end{array}$ & MS & SECAD I & Sim \\
\hline
\end{tabular}




\begin{tabular}{|c|c|c|c|c|c|c|}
\hline 11 & EDUCACAO DE JOVENS E ADULTOS & UFPB & Nordeste & PB & SECAD II & Sim \\
\hline 12 & EDUCACAO DE JOVENS E ADULTOS & UFPR & Sul & PR & SECAD I & Sim \\
\hline 13 & EDUCACAO DE JOVENS E ADULTOS & UFSC & Sul & $\mathrm{SC}$ & SECAD I & $\operatorname{Sim}$ \\
\hline 14 & EDUCACAO DE JOVENS E ADULTOS & UFU & Sudeste & MG & SECAD I & Sim \\
\hline 15 & EDUCACAO DE JOVENS E ADULTOS & UNICENTRO & Sul & PR & SECAD I & Sim \\
\hline 16 & EDUCACAO DE JOVENS E ADULTOS & UNIMONTES & Sudeste & MG & SECAD I & Sim \\
\hline 17 & EDUCACAO DE JOVENS E ADULTOS & UPE & Nordeste & PE & SECAD II & Sim \\
\hline 18 & EDUCACAO DE JOVENS E ADULTOS & UFRPE & Nordeste & PE & SECAD II & $\operatorname{Sim}$ \\
\hline 19 & $\begin{array}{c}\text { EDUCACAO DE JOVENS E ADULTOS NA } \\
\text { DIVERSIDADE }\end{array}$ & UFC & Nordeste & $\mathrm{CE}$ & SECAD III & Sim \\
\hline 20 & $\begin{array}{l}\text { EDUCACAO DE JOVENS E ADULTOS NA } \\
\text { DIVERSIDADE }\end{array}$ & UFMG & Sudeste & MG & SECAD III & Sim \\
\hline 21 & $\begin{array}{c}\text { EDUCACAO DE JOVENS E ADULTOS NA } \\
\text { DIVERSIDADE }\end{array}$ & UFPEL & Sul & RS & SECAD III & Sim \\
\hline 22 & $\begin{array}{l}\text { EDUCACAO DE JOVENS E ADULTOS NA } \\
\text { DIVERSIDADE }\end{array}$ & UFRR & Norte & RR & SECAD III & Sim \\
\hline \multirow[t]{2}{*}{23} & $\begin{array}{l}\text { EDUCACAO DE JOVENS E ADULTOS NA } \\
\text { DIVERSIDADE }\end{array}$ & UFS & Nordeste & SE & SECAD III & Sim \\
\hline & EXTENSÃO & & & & & \\
\hline 24 & EDUCACAO DE JOVENS E ADULTOS & UFBA & Nordeste & BA & SECAD I & Sim \\
\hline 25 & $\begin{array}{l}\text { EDUCACAO DE JOVENS E ADULTOS NA } \\
\text { DIVERSIDADE }\end{array}$ & UNEB & Nordeste & BA & SECAD III & Sim \\
\hline
\end{tabular}

Fonte: UAB/MEC, 2014.

Com relação aos cursos de aperfeiçoamento, verificou-se a redução de dezenove deles, conforme apontado na pesquisa de Gatti et al (2011) para dezessete, sendo sete cursos na região Nordeste; quatro, no Sudeste e Sul; e apenas um, nas regiões Centro-Oeste e Norte. A maioria dos cursos de aperfeiçoamento possui carga horária de 180 horas; apenas um deles, o da região Sudeste, apresentava duzentas horas de carga horária e nenhum polo apresentava demanda para esses cursos. Semelhantes dados foram evidenciados para os dois cursos de extensão que estão aprovados: possuem carga horária de 180 horas e não estão sendo oferecidos por qualquer polo.

Pelo exposto, no que se refere à UAB em relação à formação inicial e continuada para EJA, entendemos que a sua contribuição tem sido deficitária, pois, embora evidenciada a aprovação de cursos destinados a essa modalidade, de especialização e extensão, além dos cursos de aperfeiçoamento já existentes, observou-se que a maioria não está sendo ofertada pelos polos. Apenas quatro cursos de especialização possuíam oferta em alguns polos no período da pesquisa, restritos a quatro Estados e três regiões (Nordeste, Sul e Sudeste). O Norte nem mesmo possui cursos aprovados.

Esses dados sugerem que, embora estejam aprovados e vigentes mais cursos, num total de vinte e cinco, quatro a mais desde a pesquisa de Gatti et al (2010), na prática os cursos não estão sendo ofertados pelos 


\section{autêntica}

polos, o que requer novos estudos que tomem como objeto de pesquisas posteriores a eficácia do sistema UAB para a Educação Básica na modalidade EJA.

Outra estratégia de ação dos governos, apontada por Gatti (2011), representa um meio de alcançar os objetivos da Política Nacional de Formação Docente. Trata-se da criação de Fóruns Estaduais Permanentes de Apoio à Formação, encarregados de organizar, em regime de colaboração entre os entes federados, a formação inicial e continuada dos docentes para as redes públicas da educação básica. São eles presididos pelos Secretários de Estado da Educação e compostos por representantes dos órgãos gestores das três instâncias de governo:

[...] MEC, secretarias estaduais e municipais de Educação - estas por intermédio da União Nacional dos Dirigentes Municipais de Educação (UNDIME) - e seus respectivos conselhos estaduais e municipais de Educação; das IPESs com sede no estado; dos profissionais do magistério, por indicação de sua entidade de classe, a Confederação Nacional dos Trabalhadores em Educação (CNTE), e, quando houver, do Fórum das Licenciaturas das Instituições de Educação Superior Pública (GATTI, 2011, p. 54) $)^{5}$

A responsabilidade de apoiar, em relação à organização e ao registro de dados diversos necessários aos Fóruns, é da Secretaria de Educação Básica (SEB) do MEC, juntamente com a Diretoria de Educação Básica Presencial e a Diretoria de Educação a Distância da CAPES, porém a análise e a aprovação dos planos estratégicos cabem aos órgãos centrais do MEC. Em 2009, pelo Decreto ${ }^{\circ} 6.755$, de 29 de janeiro, foi instituída a Política Nacional de Formação de Profissionais do Magistério da Educação Básica, que disciplina a atuação da CAPES no fomento a programas de formação inicial e continuada. Nesse sentido, para atender ao art. 11, inciso III, quanto à oferta emergencial de cursos de licenciaturas e de cursos ou programas especiais dirigidos aos docentes em exercício há pelo menos três anos na rede pública de Educação Básica, foi implantado, em caráter emergencial, porém vigente até hoje, o Plano Nacional de Formação de Professores da Educação Básica (PARFOR).

Conforme Gatti et al (2011), o programa integra o Plano de Ações Articuladas (PAR), compondo o Plano de Desenvolvimento da Educação, ao qual aderiram todos os entes federados, sendo gerenciado e acompanhado pela CAPES quanto ao processo de proposição, inscrição e execução dos planos estratégicos dos Estados. Em parceria, com as IES participantes, propõem os cursos para atender às carências regionais em áreas estratégicas, respaldadas pelos Fóruns Estaduais Permanentes de Apoio à Formação Docente. Todo ano é divulgado pela CAPES o Calendário do PARFOR, em que estão definidos os prazos e as atividades a serem realizadas pelos entes federados, os Fóruns e as IES.

Conforme a CAPES/PARFOR (2014), até 2012, o PARFOR implantou 1.920 turmas, havendo cerca de 54.876 professores frequentando os cursos em turmas especiais, localizadas em 397 municípios do país. A maioria desses professores estava nas regiões Norte e Nordeste, 28.073 e 20.781, respectivamente, e o restante frequentava cursos nas demais regiões, sendo 3.422 no Sul, 1.847 no Sudeste e 753 no Centro-Oeste, conforme gráfico1, a seguir.

\footnotetext{
5 A ANFOPE, embora ausente nessa composição inicial, conquistou assento nesse fórum, nacionalmente e em todos os estados, por meio de ações posteriores à sua combativa Direção, conforme demonstra Brzezinski (2014). Como entidade acadêmica de estudos e pesquisa em Educação, tem como objetivo, em sua atuação nos Fóruns Permanentes de Apoio à Formação Docente (FPAFDs), “[...] discutir a política de formação e de valorização dos profissionais da educação, ancorada em seus princípios e práticas [...]” (BRZEZINSKI, 2013, p. 4), responsabilizando-se, por intermédio de seus titulares/pesquisadores, “[...] pelo acompanhamento e avaliação dos Planos Estratégicos Estaduais de modo propositivo, argumentando, contra argumentando e defendendo suas propostas, a fim de colaborar com o desenvolvimento do PARFOR.” (BRZEZINSKI, 2013, p. 4).
} 
GRÁFICO 1 - NÚMERO DE PROFESSORES EM TURMAS DO PARFOR POR REGIÕES 2012

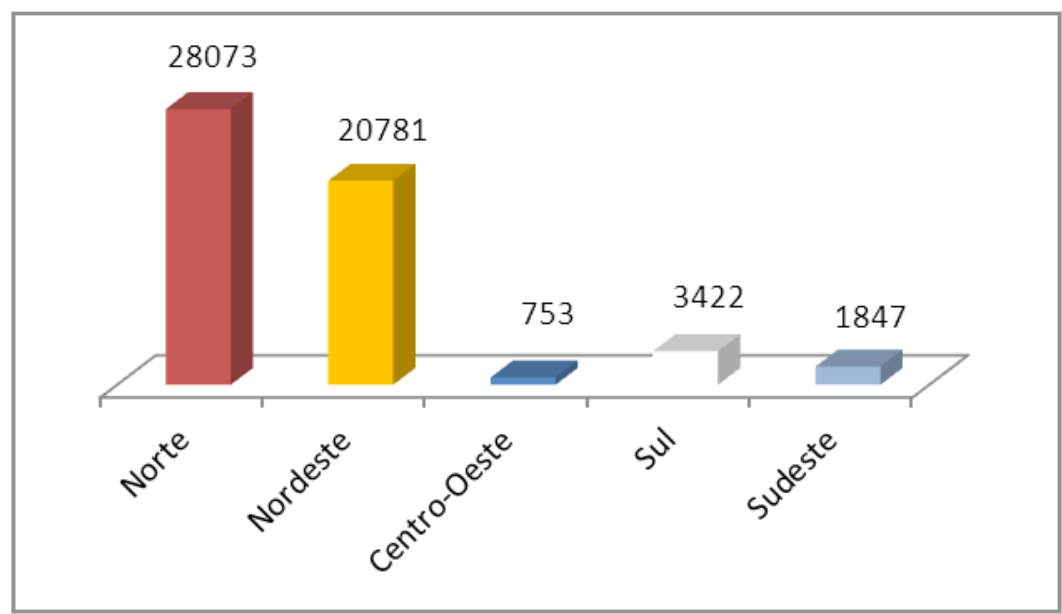

Fonte: CAPES/PARFOR (2014).

A recente pesquisa: "Observatório da Formação e Valorização Docente: Configurações e Impactos da Implementação dos Fóruns Permanentes de Apoio à Formação do Magistério," da ANFOPE, "comprova que os resultados do PARFOR são sofríveis ao se comparar vagas validadas e formados egressos em 2013, de $1^{\text {a }}$ e $2^{\mathrm{a}}$ Licenciaturas e Formação Pedagógica" (BRZEZINSKI, 2014).

Verificamos que os dispositivos para superação dos desafios da formação inicial e continuada já foram instalados e que, por outro lado, sem que sejam criadas robustas políticas públicas de formação de professores e de melhoria das suas condições de vida e de trabalho, comprometidas com a diversidade e inclusão social dos diversos segmentos da comunidade, valorização do magistério e garantia do acesso aos cursos de formação, não teremos políticas educacionais eficazes e de impactos sociais.

\section{OS DESAFIOS DOS PLANOS ESTADUAIS E MUNICIPAIS PARA FORMAÇÃO DOS FORMADORES DA EJA}

Conforme analisado até aqui, os desafios permanecem muitos em relação à formação inicial e continuada dos profissionais da educação, especialmente dos formadores de formadores da EJA. Uma via que emerge dessa discussão é o esforço constante de todos, em particular dos formadores atuantes nos cursos de licenciatura, das suas entidades representantes, a exemplo da ANFOPE, dos Fóruns Permanentes de Apoio à Formação Docente, em manterem-se acompanhando a execução e participando da atualização do PNE. Os Planos Estaduais de Educação (PEEs) e os Planos Municipais de Educação (PMEs) foram elaborados em amplos processos coletivos, dirigidos pelos Fóruns Estaduais e Municipais de Educação, embora seus desdobramentos para aprovação pelos respectivos governos, assembleias e câmaras, tenham sofrido interferências e desvios políticos, estão também a merecer acompanhamento e ajustes visando às conquistas dos movimentos da sociedade civil pela formação e pela valorização dos profissionais de educação.

Exemplificamos o caso da ANFOPE, que tem acompanhado, participado e se posicionado, nacional e localmente, diante dos desafios da formação dos profissionais da educação, categoria da qual os formadores da EJA fazem parte. Em consonância com o posicionamento no âmbito nacional da ANFOPE, ratificamos pontos importantes a serem monitorados nos Planos Estaduais e Municipais de Educação relacionados especificamente à formação: 


\section{autêntica}

- garantia de formação inicial, preferencialmente presencial e em nível superior, e a continuada, ambas de forma contextualizada na sociedade brasileira ainda marcada pela permanência de desigualdades sociais, visando à construção de uma sociedade democrática, inclusiva, justa e igualitária;

- manutenção da formação de professores no campo epistemológico da educação, fortalecendo a responsabilidade acadêmica e institucional das Faculdades e Centros de Educação como espaços articuladores dos projetos institucionais de formação;

- reformulação dos cursos de formação de professores como processo constante e contínuo, próprio ao desenvolvimento dos conhecimentos científicos e tecnológicos e das demandas socioculturais;

- superação do caráter fragmentário e dicotômico da formação do pedagogo e dos demais licenciandos, que se materializa na organização curricular, reafirmando a docência como a base da identidade de todos os profissionais da educação;

- incentivo aos cursos de formação de professores de forma massiva, mobilizando a juventude - no ensino médio e nas IES - a abraçar a profissão de educador, indicando perspectivas de atuação, carreira e aprimoramento profissional; e

- implantação de polos regionais que promovam processos de formação e acompanhamento constantes aos/ às profissionais da educação no que diz respeito às modalidades e níveis de ensino.

As diretrizes, metas e estratégias do PNE 2014-2024 aqui analisadas apresentam ambiguidades e contradições quanto à formação e à valorização do magistério, inclusive do formador de formadores (professor universitário, docente das licenciaturas), pautadas em um discurso pós-neoliberal, que ora avança em direção ao fortalecimento do poder local, ora recua, buscando o controle centralista do Estado e, ainda, propondo-se a assumir novos desafios proclamados pelos atuais movimentos sociais.

Esteve no centro desta nossa reflexão a formação de profissionais da formação, ou seja, a formação dos professores das licenciaturas, a partir do contexto da educação básica, na modalidade Educação de Jovens e Adultos. Nosso pressuposto é que são eles, pela especificidade do seu trabalho de formação de professores da educação básica e, até mesmo, da educação superior, de intelectuais fomentadores de mudanças, principais responsáveis pela reconfiguração do papel da docência nas agências formadoras e nas instituições de educação básica. Grandes e numerosas são as demandas que incidem sobre esse profissional, a quem estamos chamando de formador de formadores, a cada novo modelo assumido pelo Estado brasileiro, desde o liberalismo, ao neoliberalismo e ao pós-neoliberalismo. Há, ainda, as exigências de produtividade acadêmica no modelo taylorista, passando pela acumulação flexível. Hoje, com a transnacionalização do mercado, o processo está a exigir do profissional novos atributos como mobilidade, intercâmbio científico e político, para lidar com programas como Erasmus, Leonardo da Vinci, Sócrates, Ciência sem Fronteiras, entre outros, marcados pela (des)regulação institucional e nacional, sempre sob a égide do "Estado mínimo" e de um "mercado forte".

A retrospectiva histórica aqui apresentada e as perspectivas emergentes trazem à tona velhos temas, velhos problemas não resolvidos que nos permitem concluir que é necessário priorizar as necessidades da educação básica, inclusive da modalidade de Educação de Jovens e Adultos, frente aos requerimentos concretos do sistema educacional que queremos construir com a participação ativa dos professores no seu processo formativo, contextualizado e pertinente.

Não obstante os limites das metas do PNE, diante da realidade cabe aos formadores radicalizar suas cobranças em termos de execução, garantindo-se o acompanhamento da sociedade civil e a apresentação de propostas alternativas para sua atualização. O plano é um processo em constante movimento e contínua construção. Não é estático, nem linear. Buscamos seu movimento em espiral, respondendo aos anseios da sociedade. 


\section{autêntica}

\section{REFERÊNCIAS}

AFONSO, Almerindo Janela. Avaliação educacional: regulação e emancipação. 2. ed. São Paulo: Cortez, 2000. ANFOPE/SE. Carta ao Fórum Estadual de Educação, 28 de abril de 2015. Aracaju, 2015.

BONAMIGO, Carlos Antônio et al. História da educação básica brasileira: uma avaliação do Plano Nacional de Educação PNE 2001-2010. In: Anais da IX ANPED SUL, 2012.

BRASIL. Lei n 5.692, de 11 de agosto de 1971. Fixa Diretrizes e Bases para o ensino de $1^{\circ}$ e $2^{\circ}$ graus, e dá outras providências. Diário Oficial da União. Brasília, DF. Seção 1, p. 6377.

BRASIL. Lei no 9.394, de 20 de dezembro de 1996. Estabelece as diretrizes e bases da educação nacional. Diário Oficial da União, Brasília, DF, 23 dez. 1996. Seção 1, p. 27833.

BRASIL. Lei n 10.172, de 9 de janeiro de 2001. Aprova o Plano Nacional de Educação - PNE e dá outras providências. Diário Oficial da União. Brasília, DF. Seção 1, p. 1.

BRASIL. Lei n 13.005, de 25 de junho 2014. Aprova o Plano Nacional de Educação e dá outras providências. Diário Oficial da União. Brasília, DF. Seção 1, p. 1.

BRZEZINSKI, Iria. Fóruns Permanentes de Apoio à Formação Docente: espaço democrático mediador de políticas de formação de professores e do Regime de Colaboração?. In: XXVI Simpósio Brasileiro de Política e Administração da Educação-ANPAE, 2013, Recife. Políticas, Planos e Gestão da Educação: democratização e qualidade social. Timbaúba: Espaço Livre, 2013. v. 1. p. 1-17.

BRZEZINSKI, Iria. A formação de professores no Brasil: avanços e retrocessos. In: $7^{\circ}$ Encontro de Formação de Professores (ENFOPE) e $8^{\circ}$ Fórum Permanente de Inovação Educacional (FOPIE) - Edição Internacional. 2014. Universidade Tiradentes, Aracaju.

CAPES. Educação Básica. Parfor. Disponível em: <http://www.capes.gov.br/educacao-basica/parfor>. Acesso em 16 ago. 2014.

DI PIERRO, Maria Clara. Notas sobre a redefinição da identidade e das políticas públicas de educação de jovens e adultos no Brasil. Educação e Sociedade. Campinas, v. 26, n. 92, out. 2005.

FILGUEIRAS, Luiz; GONÇALVES, Reinaldo. A economia política do Governo Lula. São Paulo: Contraponto, 2007.

FRIGOTTO, Gaudêncio. Os circuitos da história e o balanço da educação no Brasil na primeira década do século XXI. Revista Brasileira de Educação, Rio de Janeiro: Anped. v. 16. n. 46. jan./abr. 2011. p. 235-254. Disponível em: http://www.scielo.br/scielo.php?script=sci_arttext\&pid=S1413-24782011000100013\&lng=pt \&nrm=iso. Acesso em: 15 dez. 2011.

GATTI, Bernardete Angelina. Políticas docentes no Brasil: um estado da arte. Brasília: UNESCO, 2011.

IBGE. Pesquisa nacional por amostra de domicílios 2012. Disponível em: < http://www.ibge.gov.br/home/ estatistica/populacao/trabalhoerendimento/pnad2012/default_sintese.shtm>. Acesso em: 28 abr. 2015.

IBGE. Pesquisa nacional por amostra de domicílios 2013. Disponível em: < http://www.ibge.gov.br/home/ estatistica/populacao/trabalhoerendimento/pnad2013/default_brasil.shtm>. Acesso em: 28. abr. 2015. 


\section{autêntica}

INEP. Estatísticas da educação básica. Disponível em: <http://portal.inep.gov.br/basica-censo-escolar-sinopse-sinopse>. Acesso em: 28 abr. 2015.

MACHADO, Maria Margarida. A educação de jovens e adultos no Brasil pós-Lei n 9.394/96: a possibilidade de constituir-se como política pública. Em Aberto, Brasília, v. 22, n. 82, p. 17-39, nov. 2009.

SILVA, Luciana Leandro da. A formação de formadores no contexto da transnacionalização educativa: reflexões a partir da aplicação do processo de Bolonha em Espanha e Portugal. Educação \& Sociedade. Campinas, v. 34, n. 122, p. 247-263, jan.-mar. 2013. Disponível em: http://www.cedes.unicamp.br. Acesso em: 29 abr. 2015.

MACHADO, Márcia Alves de Carvalho. Políticas educacionais no Brasil na área de Educação de Jovens e Adultos: o caso do Programa Brasil Alfabetizado em Sergipe. Dissertação de Mestrado. Programa de PósGraduação em Educação da Universidade Tiradentes. Aracaju, 2015.

MANIFESTO DOS PIONEIROS DA EDUCAÇÃO NOVA. A Reconstrução Educacional do Brasil. Revista HISTEDBR On-line. Campinas, n. especial, p.188-204, ago. 2006.

SAVIANI, Dermeval. Sistemas de ensino e planos de educação: o âmbito dos municípios. Educ. Soc. Campinas, v. 20, n. 69, p. 119-136, Dec. 1999. Disponível em: <http://www.scielo.br/scielo.php?script=sci_ arttext\&pid=S0101-73301999000400006\&Ing=en\&nrm=iso >. Acesso em: 29 abr.2015.

SAVIANI, Dermerval. Gestão federativa do sistema nacional de educação em regime de colaboração. 2012. (Apresentação de Trabalho/Outra). Disponível em: <http://www.senado.gov.br/comissoes/CE/AP/AP20121019_ DermevalSaviani_Federalismo.pdf>. Acesso em: 29 abr. 2015.

SAVIANI, Dermerval. O plano de desenvolvimento da educação: análise do projeto do MEC. Educ. Soc. Campinas , v. 28, n. 100, p. 1231-1255, out. 2007. Disponível em <http://www.scielo.br/scielo.php?script=sci_ arttext\&pid=S0101-73302007000300027\&lng=pt\&nrm=iso >. Acesso em: 29 abr. 2015.

SAVIANI, Dermeval. Finalmente em vigor o novo plano nacional de educação. A Fonte. São Sepé, 05 nov. 2014a. Disponível em: <http://grabois.org.br/portal/imprimirev.php?id_sessao=21\&id_publicacao=5073\&id_indice $=4385>$. Acesso em 02 abr. 2015.

SAVIANI, Dermeval. O atual plano nacional de educação: do projeto à aprovação final. A Fonte. São Sepé, 17 nov. 2014b. Disponível em: <http://grabois.org.br/portal/revista.int.php?id_sessao=21\&id_publicacao=5073\&id_ indice $=4388>$. Acesso em 02 abr.2015.

SAVIANI, Dermeval. Dificuldades e perspectivas em torno do plano nacional de educação. Jornal a Fonte. São Sepé, 16 dez. 2014c. Disponível em: < http://www.grabois.org.br/portal/autores/148735-40084/2014-12-16/ dificuldades-e-perspectivas-em-torno-do-plano-nacional-de-educacao>. Acesso em 02 abr. 2015.

SAVIANI, Dermeval. As implicações do novo PNE para o Brasil. Vermelho Portal. São Paulo, 30 dez. 2014d. Disponível em: <http://www.vermelho.org.br/noticia/256271-1>. Acesso em 02 abr. 2015.

SHIROMA, Eneida Oto; MORAES, Maria Célia Marcondes de; EVANGELISTA, Olinda. Política educacional. 4. ed. Rio de Janeiro: Lamparina, 2011. 
